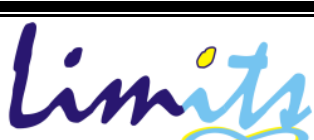

Limits: Journal of Mathematics and Its Applications

E-ISSN: $2579-8936$

P-ISSN: $1829-605 \mathrm{X}$

Vol. 16, No. 2, Desember 2019, 87-93

DOI: http://dx.doi.org/10.12962/limits.v16i2.5594

\title{
Dimensi Metrik Hasil Operasi Tertentu pada Graf Petersen Diperumum
}

\author{
${ }^{1}$ Asmiati, ${ }^{2}$ Ahmad Ari Aldino, ${ }^{1}$ Notiragayu, ${ }^{1}$ La Zakaria, ${ }^{1}$ Muslim Anshori \\ ${ }^{1}$ Jurusan Matematika, FMIPA, Universitas Lampung \\ ${ }^{2}$ Jurusan Teknik Elektro, Fakultas Sains dan Teknologi, Universitas Nahdlatul Ulama Lampung \\ e-mail: asmiati.1976@fmipa.unila.ac.id
}

\begin{abstract}
Abstrak
Misalkan $G=(V, E)$ graf terhubung dan $u, v \in V(G)$, jarak titik $u$ dan $v$ yang dinotasikan dengan $d(u, v)$ adalah panjang lintasan terpendek dari kedua titik tersebut. Misalkan $W=\left\{w_{1}, w_{2}, w_{3}, \ldots, w_{k}\right\} \subseteq$ $V(G)$, representasititik $v \in V(G)$ terhadap $W$ adalah urutan $k$-vektor, $r(v \mid W)=\left(d\left(v, w_{1}\right), d\left(v, w_{2}\right), \ldots\right.$, $\left.d\left(v, w_{k}\right)\right)$. Himpunan $W$ disebut himpunan pembeda, jika $r(u \mid W) \neq r(v \mid W)$ untuk setiap dua titik berbeda $u, v \in V(G)$. Kardinalitas minimum dari himpunan pembeda $W$ disebut dimensi metrik dari $G$, dinotasikan dengan $\beta(G)$. Pada penelitian ini dibahas tentang dimensi metrik dari hasil operasi tertentu pada graf Petersen diperumum.
\end{abstract}

Kata Kunci: Himpunan pembeda, dimensi metrik, graf Petersen diperumum.

\section{Abstract}

Let $G=(V, E)$ be a connectedgraphand $u, v \in V(G)$, the distanceof $u$ and $v$, denoted byd $(u, v)$ is the length of the shortest path of these two vertices. Define $W=\left\{w_{1}, w_{2}, w_{3}, \ldots, w_{k}\right\} \subseteq V(G)$, representation of $v \in V(G)$ with respect to $W$ is the $k$-vector, $r(v \mid W)=\left(d\left(v, w_{1}\right), d\left(v, w_{2}\right), \ldots\right.$, $\left.d\left(v, w_{k}\right)\right)$. The subset $W$ is a resolving set, if, $r(u \mid W) \neq r(v \mid W)$ for every two distinct vertices $u, v \in$ $V(G)$. The minimum cardinality of resolving set $W$ is called the metric dimension of $G$, denoted by $\beta(G)$. In this paper, we discuss about metric dimension of certain operating result of generalized Petersen graphs. Keywords: Resolving set, metric dimension, generalized Petersen graph.

\section{Pendahuluan}

Suatu graf $G=(V, E)$ terdiri atas himpunan tak kosong $V(G)$ yang disebut himpunan titik dan himpunan sisi $E(G)$ (mungkin kosong). Sisi suatu graf dapat dinyatakan sebagai pasangan tak terurut dari dua titik di $V(G)$.

Salah satu konsep kajian penting dalam teori graf adalah dimensi metrik. Konsep tentang dimensi metrik dari suatu graf diperkenalkan secara terpisah oleh Slater [1] pada tahun 1975. Slater mengaitkan permasalahan dimensi metrik untuk menentukan banyaknya alat pendeteksi sonar dalam suatu jaringan. Alat-alat tersebut digunakan sebagai acuan sehingga lokasi dari setiap posisi dalam jaringan dapat diketahui. Lokasi ini direpresentasikan sebagai vektor jarak dari posisi itu terhadap semua alat pendeteksi tersebut. 
Berikut ini diberikan definisi dimensi metrik graf yang diambil dari Chartrand dkk.[2]. Misalkan $G=(V, E)$ adalah suatu graf dengan himpunan titik $V(G)$ yang berhingga, dan himpunan sisi $E(G)$. Jarak dari dua titik berbeda $v, w \in V(G)$, dinotasikan dengan $d(v, w)$, adalah panjang lintasan terpendek dari $v$ ke $w$ di $G$. Misalkan $W=\left\{w_{1}, w_{2}, w_{3}, \ldots, w_{k}\right\} \subseteq V(G)$ adalah subhimpunan titik terurut dari $V(G)$. Untuk setiap titik $v \in V(G)$, representasi titik $v$ terhadap $W$ didefinisikan sebagai $k$-pasang terurut $r(v \mid W)=\left(d\left(v, w_{1}\right), d\left(v, w_{2}\right), \ldots, d\left(v, w_{k}\right)\right)$. Himpunan $W$ dikatakan sebagai himpunan pembeda dari $G$ jika setiap dua titik berbeda $x, y \in V(G)$ berlaku $r(x \mid W) \neq r(y \mid W)$. Basis dari $G$ adalah himpunan pembeda dari $G$ dengan kardinalitas terkecil. Adapun kardinalitas dari basis $W$ didefinisikan sebagai dimensi metrik, dan dinotasikan dengan $\beta(G)$.

Secara umum, penentuan dimensi metrik dari suatu graf merupakan permasalahan yang sukar. Hingga saat ini, belum ada algoritma yang efektif yang dapat digunakan untuk menentukan basis metrik untuk sebarang graf. Hal tersebut disebabkan oleh beragamnya bentuk dan struktur dari graf. Walaupun demikian, beberapa kriteria, batasan, dan dimensi metrik dari beberapa kelas tertentu, sudah dapat ditunjukkan. Chartrand dkk.[2] telah menunjukkan bahwa graf $G$ yang berdimensi 1 hanyalah graf lintasan. Lebih jauh lagi, mereka berhasil mengkarakterisasi semua graf $G$ dengan $n$ titik yang mempunyai $\beta(G)=n-1$, dan $\beta(G)=n-2$. Peneliti lainnya, Hernando dkk. [3] telah berhasil menentukan semua kelas graf berorde $n$ dan berdiameter $d$, serta memiliki dimensi metrik $(n-d)$.

Para peneliti juga banyak yang menyederhanakan permasalahan ini dengan menerapkannya pada kelas-kelas graf tertentu yang relatif sederhana. Chartrand dkk. [2] telah menentukan dimensi metrik dari graf lingkaran, lintasan, dan graf lengkap. Adapun Bača dkk. [4] telah mengkaji dimensi metrik dari beberapa kelas graf reguler. Dimensi metrik dari keluarga graf lainnya, yaitu graf pohon, telah dipelajari oleh Slater [1]. Pada tahun 2013, Suhadi dkk. [5] telah mengkaji dimensi metrik dari graf multipartit lengkap,

Berikut ini diberikan definisi graf Petersen dan graf Petersen diperumum yang pertama kali diperkenalkan oleh Watkins pada tahun 1969 [6]. Graf Petersen adalah graf dengan 5 titik dan 10 sisi, setiap titiknya berderajat 3 dan setiap titik pada siklus luar menempel dengan sebuah sisi pada siklus dalam, siklus dalam dan luar masing-masing terdiri dari 5 titik. Graf Petersen diperumum $P_{n, k}, n \geq 3$ dan $1 \leq k \leq\lceil(n-1) / 2\rceil$, terdiri dari $n$-siklus luar $u_{1}, u_{2}, \ldots, u_{n}$, himpunan $n$ jarijari $u_{i} v_{i}, 1 \leq i \leq n$, dan $n$ sisi $v_{i} v_{i+k}, 1 \leq i \leq n$, dengan indeks $i$ diambil dari modulo $n$. Graf Petersen $P_{n, 1}$ berbentuk prisma yang didefinisikan sebagai perkalian Cartesian dari graf siklus $C_{n}$ dan lintasan $P_{2}$ 


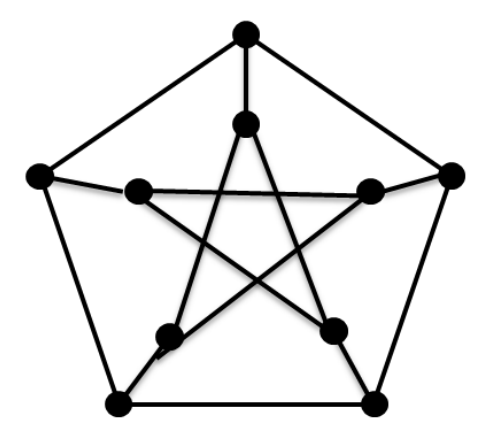

Gambar 1. Graf Petersen

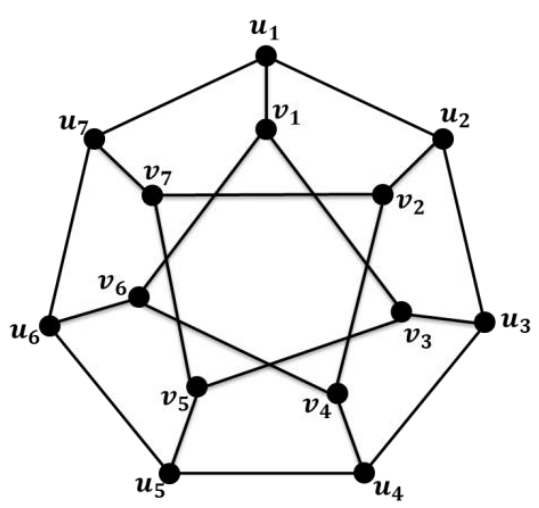

Gambar 2. Contoh graf Petersen diperumum $P_{7,2}$

Dimensi metrik dari graf Petersen diperumum telah ditentukan oleh Ahmad dkk. [7]. Kasus khusus penentuan dimensi metrik untuk graf Petersen diperumum diperoleh oleh Imran dkk. [8], selanjutnya Mulyono dan Wulandari [9] memperoleh hasil bahwa dimensi metrik graf Petersen diperumum $P_{n, 1}$ adalah 2 untuk $n$ ganjil dan 3 untuk $n$ genap.

Berikut ini diberikan definisi operasi tertentu dari graf Petersen diperumum, dinotasikan dengan $s P_{n, k}$. Diberikan $s \geq 1$ graf Petersen diperumum $P_{n, k}$. Titik-titik pada siklus luar $u_{i}, i \in$ $[1, n]$ dari $P_{n, k}$ yang ke $t, t \in[1, s], s \geq 1$ dinotasikan dengan $u_{i}^{t}$, sedangkan titik-titik pada siklus dalam $v_{i}, i \in[1, s]$ dari $P_{n, k}$ yang ke-t, $t \in[1, s], s \geq 1$ dinotasikan dengan $v_{i}^{t}$. Operasi tertentu graf Petersen diperumum $s P_{n, k}$ diperoleh dari $s \geq 1$ graf $P_{n, k}$, dengan setiap titik pada siklus luar $u_{i}^{t}, i \in[1, n], t \in[1, s]$ dihubungkan oleh sebuah sisi, $u_{i}^{t} u_{i}^{t+1}, t \in[1, s-1], s \geq 2$. Jadi pada $s P_{n, k}$, nilai $s \geq 1$ menyatakan banyaknya layer yang terbentuk. Pada penelitian ini ditentukan bentuk umum dimensi metrik dari hasil operasi tertentu graf Petersen diperumum $s P_{n, 1}$. 


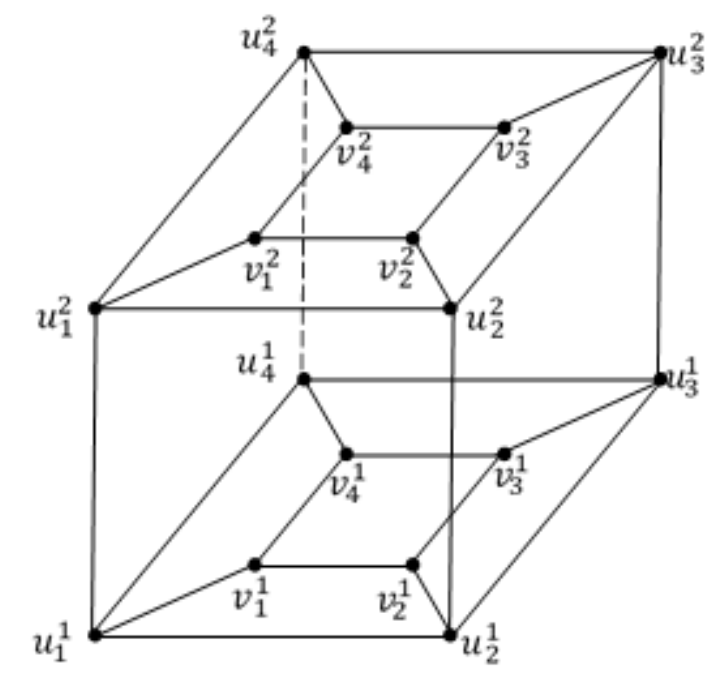

Gambar 3. Hasil operasi graf Petersen diperumum $2 P_{4,1}$

\section{Metode Penelitian}

Langkah-langkah yang dilakukan untuk menentukan dimensi metrik dari graf Petersen diperumum $s P_{n, 1}$ adalah menentukan himpunan pembeda dari $V\left(s P_{n, 1}\right)$ untuk $n \geq 3$, sedemikian sehingga memenuhi persyaratan. Misalkan $W=\left\{w_{1}, w_{2}, w_{3}, \ldots, w_{k}\right\} \subseteq V(G)$ adalah subhimpunan titik terurut dari $V(G)$. Selanjutnya ditentukan representasi semua titik di $V\left(s P_{n, 1}\right)$ terhadap $W$. Jika setiap dua titik berbeda $x, y \in V\left(s P_{n, 1}\right)$ berlaku $r(x \mid W) \neq r(y \mid W)$, maka $W$ disebut himpunan pembeda. Himpunan pembeda dengan kardinalitas terkecil disebut basis dan kardinalitas basis itu yang dimaksud dengan dimensi metrik dari $s P_{n, 1}$.

\section{Hasil dan Pembahasan}

Pada bagian ini akan didiskusikan dimensi metrik dari hasil operasi tertentu graf Petersen diperumum, yang dinotasikan dengan $s P_{n, 1}$ untuk $s \geq 1, n \geq 3$.

Teorema: Dimensi metrik dari hasil operasi tertentu dari graf Petersen diperumum $s P_{n, 1}$ adalah $s+1$ untuk $n \geq 3$ ganjil dan $s+2$ untuk $n \geq 4$ genap.

\section{Bukti :}

\section{Kasus 1. $n \geq 3$ ganjil.}

Pada hasil operasi tertentu dari graf Petersen diperumum $s P_{n, 1}$ untuk $n \geq 3$ ganjil, berdasarkan hasil observasi diperoleh himpunan pembeda $W=\left\{u_{1}^{1}, u_{j}^{1}, \ldots, u_{j}^{s}\right\}$ dengan $j=\frac{n+1}{2}$, dan $k=$ $\{2, \ldots, s\}$ merupakan nilai $s$ dari masing-masing titik dalam himpunan pembeda. Jika terdapat penambahan pada layer $s$ maka penambahan representasi di layer sebelumnya adalah $u_{j}^{k-1}+1$ dan 
tidak mengikuti kode yang terdapat pada Tabel 1. Representasi titik-titik graf $s P_{n, 1}$ dengan himpunan pembeda $W$ dapat dilihat pada Tabel 1 berikut ini,

Tabel 1. Representasi titik-titik graf $s P_{n, 1}$ untuk $n$ ganjil dengan himpunan pembeda $W$.

\begin{tabular}{|c|c|c|c|c|c|c|c|}
\hline \multirow{2}{*}{$\begin{array}{c}\text { Titik di } \\
\text { graf }\end{array}$} & \multicolumn{7}{|c|}{ Basis yang diambil } \\
\hline & $u_{1}^{1}$ & $u_{j}^{1}$ & $u_{j}^{2}$ & $u_{j}^{3}$ & $u_{j}^{4}$ & $\ldots$ & $u_{j}^{S}$ \\
\hline$u_{1}^{s}$ & $s-1$ & $j+(s-2)$ & $j+(s-3)$ & $j+(s-4)$ & $j+(s-5)$ & $\ldots$ & $j-1$ \\
\hline$u_{2}^{s}$ & $s$ & $j+(s-3)$ & $j+(s-4)$ & $j+(s-5)$ & $j+(s-6)$ & $\ldots$ & $j-2$ \\
\hline$\overline{u_{3}^{s}}$ & $s+1$ & $j+(s-4)$ & $j+(s-5)$ & $j+(s-6)$ & $j+(s-7)$ & $\ldots$ & $j-3$ \\
\hline$\vdots$ & & & & & & & \\
\hline$u_{j}^{s}$ & $j+(s-2)$ & $s-1$ & $s-2$ & $s-3$ & $s-4$ & $\ldots$ & 0 \\
\hline$u_{j+1}^{s}$ & $j+(s-2)$ & $S$ & $s-1$ & $s-2$ & $s-3$ & $\ldots$ & 1 \\
\hline$\vdots$ & & & & & & & \\
\hline$u_{n}^{s}$ & $s$ & $j+(s-2)$ & $j+(s-3)$ & $j+(s-4)$ & $j+(s-5)$ & $\ldots$ & $j-1$ \\
\hline$v_{1}^{s}$ & $S$ & $j+(s-1)$ & $j+(s-2)$ & $j+(s-3)$ & $j+(s-4)$ & $\ldots$ & $j$ \\
\hline$v_{2}^{s}$ & $s+1$ & $j+(s-2)$ & $j+(s-3)$ & $j+(s-4)$ & $j+(s-5)$ & $\ldots$ & $j-1$ \\
\hline$v_{3}^{s}$ & $s+2$ & $j+(s-3)$ & $j+(s-4)$ & $j+(s-5)$ & $j+(s-6)$ & $\ldots$ & $j-2$ \\
\hline$\vdots$ & & & & & & & \\
\hline$\overline{v_{j}^{S}}$ & $j+(s-1)$ & $s$ & $s-1$ & $s-2$ & $s-3$ & $\ldots$ & 1 \\
\hline$v_{j+1}^{S}$ & $j+(s-1)$ & $s+1$ & $s$ & $s-1$ & $s-2$ & $\ldots$ & 2 \\
\hline$\vdots$ & & & & & & & \\
\hline$v_{n}^{s}$ & $s+1$ & $j+(s-1)$ & $j+(s-2)$ & $j+(s-3)$ & $j+(s-4)$ & $\ldots$ & $j$ \\
\hline
\end{tabular}

Berdasarkan Tabel 1 dapat dilihat bahwa representasi semua titik di $V\left(s P_{n, 1}\right)$ berbeda. Akibatnya $W$ merupakan himpunan pembeda terkecil dengan $|W|=s+1$. Jadi diperoleh, $\beta\left(s P_{n, 1}\right)=s+$ 1 , untuk $n \geq 3$ ganjil.

\section{Kasus 2. $n \geq 4$ Genap.}

Pada hasil operasi graf Petersen diperumum $s P_{n, 1}$ untuk $n \geq 4$ genap, berdasarkan hasil observasi diperoleh himpunan pembeda $W=\left\{u_{1}^{1}, u_{j}^{1}, u_{n}^{1}, \ldots, u_{n}^{s}\right\}$, dengan $j=\frac{n+2}{2}$, dan $k=\{2, \ldots, s\}$ merupakan nilai $s$ dari masing-masing titik dalam himpunan pembeda. Hal yang sama pada pembuktian sebelumnya, jika terdapat penambahan pada layer $s$ maka penambahan representasi di layer sebelumnya adalah $u_{j}^{k-1}+1$ dan tidak mengikuti kode yang terdapat di Tabel 2. Representasi titik-titik di $V\left(s P_{n, 1}\right)$ dengan himpunan pembeda $W$ dapat dilihat pada Tabel 2 berikut ini. 
Tabel 2. Representasi titik-titik $V\left(s P_{n, 1}\right)$ untuk $n \geq 4$ genap dengan himpunan pembeda $W$.

\begin{tabular}{|c|c|c|c|c|c|c|c|}
\hline \multirow{2}{*}{$\begin{array}{l}\text { Titik di } \\
\text { graf }\end{array}$} & \multicolumn{7}{|c|}{ Basis yang diambil } \\
\hline & $\overline{u_{1}^{1}}$ & $u_{j}^{1}$ & $\overline{u_{n}^{1}}$ & $u_{n}^{2}$ & $\overline{u_{n}^{3}}$ & $\ldots$ & $\boldsymbol{u}_{n}^{s}$ \\
\hline$u_{1}^{s}$ & $s-1$ & $j+(s-2)$ & $s$ & $s-1$ & $s-2$ & $\ldots$ & 1 \\
\hline $\boldsymbol{u}_{2}^{s}$ & $s$ & $j+(s-3)$ & $s+1$ & $s$ & $s-1$ & $\ldots$ & 2 \\
\hline$\overline{u_{3}^{s}}$ & $s+1$ & $j+(s-4)$ & $s+2$ & $s+1$ & $s$ & ... & 3 \\
\hline $\begin{array}{l}\cdot \\
\cdot \\
.\end{array}$ & & & & & & & \\
\hline $\boldsymbol{u}_{j}^{s}$ & $j+(s-2)$ & $s-1$ & $j+(s-3)$ & $j+(s-4)$ & $j+(s-5)$ & $\ldots$ & $j-2$ \\
\hline$u_{j+1}^{s}$ & $j+(s-3)$ & $s$ & $j+(s-4)$ & $j+(s-5)$ & $j+(s-6)$ & $\ldots$ & $\overline{j-3}$ \\
\hline $\begin{array}{l}\cdot \\
\cdot \\
\cdot\end{array}$ & & & & & & & \\
\hline $\boldsymbol{u}_{n}^{s}$ & $s$ & $j+(s-3)$ & $s-1$ & $s-2$ & $s-3$ & $\ldots$ & 0 \\
\hline$v_{1}^{s}$ & $S$ & $j+(s-1)$ & $s+1$ & $S$ & $s-1$ & $\ldots$ & 2 \\
\hline $\bar{v}_{2}^{S}$ & $s+1$ & $j+(s-2)$ & $s+2$ & $s+1$ & $S$ & $\ldots$ & 3 \\
\hline$v_{3}^{s}$ & $s+2$ & $j+(s-3)$ & $s+3$ & $s+2$ & $s+1$ & $\ldots$ & 4 \\
\hline $\begin{array}{l}\cdot \\
\cdot \\
.\end{array}$ & & & & & & & \\
\hline $\bar{v}_{j}^{s}$ & $j+(s-1)$ & $s$ & $j+(s-2)$ & $j+(s-3)$ & $j+(s-4)$ & $\ldots$ & $j-1$ \\
\hline$v_{j+1}^{s}$ & $j+(s-2)$ & $s+1$ & $j+(s-3)$ & $j+(s-4)$ & $j+(s-5)$ & $\ldots$ & $j-2$ \\
\hline $\begin{array}{l}\cdot \\
\cdot \\
\cdot\end{array}$ & & & & & & & \\
\hline$\overline{v_{n}^{S}}$ & $s+1$ & $j+(s-2)$ & $s$ & $s-1$ & $s-2$ & $\ldots$ & 1 \\
\hline
\end{tabular}

Dari hasil tersebut diperoleh bahwa representasi titik-titik di $s P_{n, 1}$ terhadap $W$ berbeda. Ini menunjukkan bahwa $W$ merupakan himpunan pembeda terkecil dengan kardinalitasnya adalah $s+2$. Jadi diperoleh $\beta\left(s P_{n, 1}\right)=s+2$.

Berikut ini akan diberikan contoh dimensi metrik graf Petersen diperumum $2 P_{4,1}$. Pada graf $2 P_{4,1}$, diperoleh $s=2$ dan $j=3$ sehingga $W=\left\{u_{1}^{1}, u_{3}^{1}, u_{4}^{1}, u_{4}^{2}\right\}$ maka representasi titiknya adalah $r\left(u_{1}^{1} \mid W\right)=(0,2,1,2), r\left(u_{2}^{1} \mid W\right)=(1,1,2,3), r\left(u_{3}^{1} \mid W\right)=(2,0,1,2), r\left(u_{4}^{1} \mid W\right)=(1,1,0,1)$, $r\left(v_{1}^{1} \mid W\right)=(1,3,2,3), r\left(v_{2}^{1} \mid W\right)=(2,2,3,4), r\left(v_{3}^{1} \mid W\right)=(3,1,2,3), r\left(v_{4}^{1} \mid W\right)=(2,2,1,2)$, $r\left(u_{1}^{2} \mid W\right)=(1,3,2,1), r\left(u_{2}^{2} \mid W\right)=(2,2,3,2), r\left(u_{3}^{2} \mid W\right)=(3,1,2,1), r\left(u_{4}^{2} \mid W\right)=(2,2,1,0)$, $r\left(v_{1}^{2} \mid W\right)=(2,4,3,2), r\left(v_{2}^{2} \mid W\right)=(3,3,4,3), r\left(v_{3}^{2} \mid W\right)=(4,2,3,2), r\left(v_{4}^{2} \mid W\right)=(3,3,2,1)$. 
Representasi semua titik di $V\left(2 P_{4,1}\right)$ terhadap $W$ adalah berbeda, maka $W$ adalah partisi pembeda dengan kardinalitas terkecil. Akibatnya, $\beta\left(2 P_{4,1}\right)=4$. Sebagai contoh dapat dilihat pada Gambar 3, partisi pembeda minimalnya adalah $W=\left\{u_{1}^{1}, u_{3}^{1}, u_{4}^{1}, u_{4}^{2}\right\}$.

\section{Simpulan}

Dimensi metrik hasil operasi tertentu dari graf Petersen diperumum $s P_{n, 1}$ adalah $s+1$ untuk $n \geq 3$ ganjil dan $s+2$ untuk $n \geq 4$ genap.

\section{Daftar Pustaka}

[1] P.J. Slater., "Leaves of Trees," in Proc. $6^{\text {th }}$ Southeastern Conf. on Combinatorics, Graph Theory, and Computing, Congressus Numerantium, vol. 14, pp 549-559, 1975.

[2] G. Chartrand, L. Eroh, M. A. Johnson, and O.R. Oellermann, "Resolvability in graphs and the metric dimension of a graph," Discrete Applied Mathematics vol. 105, pp. 99$113,2000$.

[3] C. Hernando, M. Mora, I.M. Pelayo, C. Seara, and D.R. Wood, "Extremal graph theory for metric dimension and diameter,"Electronic Journal of Combinatorics, vol. 17(30), pp.1-28, 2010.

[4] M. Bača, E.T. Baskoro, A.N.M. Salman, S.W. Saputro, and D. Suprijanto, "The metric dimension of regular bipartite graph", Bulletin Mathématique de la Société des Sciences Mathématiques de Roumanie, vol. 54 (102), pp. 15-28, 2011.

[5] S.W. Saputro, E.T. Baskoro, A.N.M. Salman, and D. Suprijanto, "The metric dimension of a complete $n$-partite graph and its Cartesian product with a path," Journal of Combinatorial Mathematics and Combinatorial Computing, vol. 71, pp. 283-293, 2009.

[6] M. E. Watkins, "A Theorem on Tait Colorings with an Application to the Generalized Petersen Graphs,” J. Comb. Theory, vol. 164, pp. 152-164, 1969.

[7] S. Ahmad, M. A. Chaudhry, I. Javaid, and M. Salman, "On The Metric Dimension of Generalized Petersen Graph”, Quastiones Mahematicae, vol.36, pp.421-435, 2013.

[8] M. Imran, A. Q. Baig, M. K. Shafiq, M.K, and I. Tomecu, "On Metric Dimension of Generalized Petersen Graph", Ars Combinatoria, vol.117, pp. 113-130, 2014.

[9] Mulyono and Wulandari, "The Metric Dimension of Friendship Graph $F_{n}$, Lollipop Graph $\mathrm{L}_{\mathrm{m}, \mathrm{n}}$ and Petersen Graph $\mathrm{P}_{\mathrm{n}, \mathrm{m}}$," Bulletin of Mathematics. vol. 08, pp.117-124, 2016. 